\title{
A central role for chromosome breakage in gene amplification, deletion formation, and amplicon integration
}

\author{
Brad Windle, ${ }^{1}$ Bruce W. Draper, ${ }^{2}$ Yuxin Yin, Stephen O'Gorman, and Geoffrey M. Wahl \\ Gene Expression Laboratory, The Salk Institute for Biological Studies, La Jolla, California 92037 USA
}

\begin{abstract}
A CHO cell line with a single copy of the DHFR locus on chromosome $\mathrm{Z2}$ was used to analyze the structure of the amplification target and products subsequent to the initial amplification event. Dramatic diversity in the number and cytogenetic characteristics of DHFR amplicons was observed as soon as eight to nine cell doublings following the initial event. Two amplicon classes were noted at this early time: Small extrachromosomal elements and closely spaced chromosomal amplicons were detected in $30-40 \%$ of metaphases in six of nine clones, whereas three of nine clones contained huge amplicons spanning $>\mathbf{5 0}$ megabases. In contrast, the incidence of metaphases containing extrachromosomal amplicons fell to $1-2 \%$ in cells analyzed at 30-35 cell doublings, and most amplicons localized to rearranged or broken derivatives of chromosome $\mathrm{Z} 2$ at this time. Breakage of the $\mathrm{Z} 2$ chromosome near the DHFR gene, and deletion of the DHFR gene and flanking DNA was also observed in cells that had undergone the amplification process. To account for these diverse cytogenetic and molecular consequences of gene amplification, we propose that chromosome breakage plays a central role in the amplification process by (1) generating intermediates that are initially acentric and lead to copy number increase primarily by unequal segregation, (2) creating atelomeric ends that are either incompletely replicated or resected by exonucleases to generate deletions, and (3) producing recombinogenic ends that provide preferred sites for amplicon relocalization.
\end{abstract}

[Key Words: Gene amplification; chromosome breakage; deletion; gene targeting; genetic instability]

Received September 13, 1990; revised version accepted December 19, 1990.

Chromosomes in cancer cells are often rearranged relative to their counterparts in normal cells. Such changes can alter the organization or change the copy number of genes normally involved in the control of cell growth and differentiation, and the ensuing alterations in gene expression affect the proliferative capacity of the cell (e.g., see Bishop 1987). Because the large-scale chromosomal alterations that arise in cancer cells occur infrequently in normal cells (Tlsty 1990; Wright et al. 1990), it is likely that control mechanisms that safeguard chromosomal integrity are abrogated in the development of malignancy. Thus, understanding the molecular basis of common chromosomal rearrangements should provide insight into the mechanisms that maintain chromosomal integrity and how they may have gone awry in the development of malignancy.

Our studies have focused on gene amplification, a process that increases gene copy number and elevates the expression of a variety of proto-oncogenes in vivo and a large number of genes that confer drug resistance in vitro (e.g., for references, see Stark et al. 1989; Wahl 1989).

\footnotetext{
${ }^{1}$ Cancer Therapy and Research Center of South Texas, University of Texas, San Antonio, Texas 78229 USA; ${ }^{2}$ Fred Hutchinson Cancer Research Institute, Seattle, Washington 98195 USA.
}

The amplification process can be divided into two phases. (1) In the early phase, the amplified sequences are typically genetically unstable. Cells with unstable amplification products are usually isolated by selection with a single low concentration of selective agent and passaged for a "minimal" time prior to analysis. In most cases, the instability derives from acentric extrachromosomal molecules ranging in size from $\sim 100 \mathrm{~kb}$ to $>2000$ kb [e.g., episomes and double minute chromosomes (DMs); for references, see Cowell 1982; Wahl 1989). However, in one instance, unstable early stage amplification products have been postulated to be chromosomal (Saito et al. 1989). (2) In the late phase, the amplified sequences are typically genetically stable, and they are detected in cells subjected to multiple step selection or extensive cell culture. Where extrachromosomal elements were detected in early stage cells, their integration into one or more chromosomal sites can generate a stable amplification phenotype at later stages (e.g., for a review and references, see Wahl 1989; Von Hoff et al. 1990).

Cytogenetic and molecular structures detected in late stage cells may be generated by processes unrelated to those that produce the initial unit of amplification on "amplicon" (for review, see Stark et al. 1989; for a recent 
example, see Ruiz and Wahl 1990). Thus, deductions about mechanisms for generating the initial amplicons should depend on analyzing amplification events as close as possible to the occurrence of the initial event. However, most of the proposed mechanisms for gene amplification derive from analyses of the structures present in late-stage cells (for recent reviews, see Stark et al. 1989; Wahl 1989). Furthermore, unambiguous analysis of the target site subsequent to amplification has been difficult because most of the target genes studied thus far are autosomal and present in at least two copies in the heteroploid cell lines often employed. Studies that circumvented this problem by using gene transfer to introduce an amplifiable gene into a single chromosomal site have indicated that deletion of the transfected gene occurred during amplification, but it is possible that these results reflect a special property of the insertion sites analyzed (e.g., see Ruiz and Wahl 1988, 1990). Amplification of an endogenous $\mathrm{N}-m y c$ gene in neuroblastoma cells has also been linked recently with deletion of one N-myc gene copy (Hunt et al. 1990), but only one example from a single amplification event was examined, and it is uncertain whether deletion was a primary event in this case. In contrast, another study concluded that deletion was not involved in the amplification of endogenous CHO DHFR genes (Trask and Hamlin 1989). Thus, whether deletion of the target locus is a common element of the amplification process at different loci, or even within a single locus, remains an important and controversial issue.

This paper examines the early products generated during the amplification of an endogenous dihydrofolate reductase (DHFR) gene in CHO cell line UA21, which contains only a single DHFR locus on chromosome $\mathrm{Z} 2$ (Urlaub et al. 1986). This experimental system enabled us to investigate directly the structures of the amplification target and amplicons. The results implicate chromosome breakage as an early or initial event in gene amplification, as suggested by previous cytogenetic studies (e.g., see Biedler et al. 1988), and they indicate that the initial amplicons are most frequently acentric elements. In contrast to a recent report (Trask and Hamlin 1989), we show that cells having undergone DHFR gene amplification are prone to deletion of the DHFR gene and flanking sequences. A model is presented in which chromosome breakage generates the initial acentric amplification intermediates, produces atelomeric ends whose shortening creates deletions, and provides substrates for the targeted insertion of amplicons.

\section{Results}

\section{Early events generate unstable DHFR amplicons}

Fluorescent in situ hybridization (FISH) was used to characterize the number and cytogenetic features of DHFR amplicons in methotrexate (Mtx)-resistant subclones of UA21 cells approximately eight to nine cell doublings after application of selection. The selection protocol was designed to favor isolation of recent ampli- fication events. Innocula of 100 UA21 cells were expanded to $\sim 2 \times 10^{5}$ cells and then challenged, in a single step, with the lowest concentration of Mtx that would enable isolation of cell clones with DHFR gene amplification (see Materials and methods). Because cells with amplification pre-exist at frequencies of $\sim 10^{-5}$ to $10^{-6}$ (Kempe et al. 1976; Tlsty et al. 1989), most of the events that generated clones should have occurred within one or two cell doublings of application of selection. Informative preparations were obtained from 10 clones. Of these, nine showed evidence of DHFR gene amplification. The exception, which probably resisted Mtx by one of several other known mechanisms (Flintoff et al. 1978), was not examined further.

Individual cells of each Mtx-resistant clone frequently contained more independent $D H F R$-specific FISH signals than the parental UA21 cells, and there was substantial heterogeneity in the number of signals displayed by individual cells in each clone (Fig. 1; Table 1). In UA21 cells, $80 \%$ of interphase nuclei showed either one or a clustered pair of yellowish signals (Fig. 1a); no additional signals were observed. In contrast, in each Mtx-resistant single cell "clone," between $30 \%$ and $66 \%$ of interphase nuclei showed more than two signals arrayed as a loose cluster or dispersed throughout the nuclei (Fig. $1 \mathrm{~b}, \mathrm{c}, \mathrm{f})$. The interphase cells shown in Figure $1, b$ and $f$, effectively illustrate the variation in signal number that was routinely observed in each clone.

Examination of the metaphase spreads in these same preparations showed that the DHFR FISH signals observed in interphase nuclei of Mtx-resistant clones were generated by a process that frequently affected the integrity of the amplification target. For the parental UA21 line, $43 / 50(86 \%)$ of the metaphase spreads examined showed one or a pair of FISH signals approximately onethird of the distance between the centromere and the telomere on the long arm of the submetacentric chromosome Z2 (see Fig. 3A; Funanage and Myoda 1986; Trask and Hamlin 1989); no signal was observed in the remaining seven spreads (Table 1). In contrast, in Mtx-resistant clones, only $15-50 \%$ of the metaphases examined contained a chromosome exhibiting a wild-type hybridization signal at the native position (e.g., the chromosome in the center of Fig. 1h with a single pair of fluorescent dots), This reduction in the fraction of wild-type sites with single-copy hybridization is statistically significant $(P<0.005)$.

The nine clones analyzed could be divided into two classes based on the amplicon size and the presence of small extrachromosomal elements. In six clones, the amplicons were relatively small, and DHFR-specific hybridization was detected in small extrachromosomal elements (Fig. 1c,d) or in clusters in chromosomes. Within clusters, chromosomally localized amplicons displayed little or no propidium fluorescence between adjacent DHFR signals (e.g., see the two clusters of signals in the dicentric chromosome in Fig. $1 \mathrm{~g}$ ). Individual cells within a single clone also manifested differences in the locations of DHFR FISH signals. For example, the cells in Figure 1, $\mathrm{d}$ and $\mathrm{e}$, descended from a single progenitor, yet 
Downloaded from genesdev.cshlp.org on April 26, 2023 - Published by Cold Spring Harbor Laboratory Press

Windle et al.
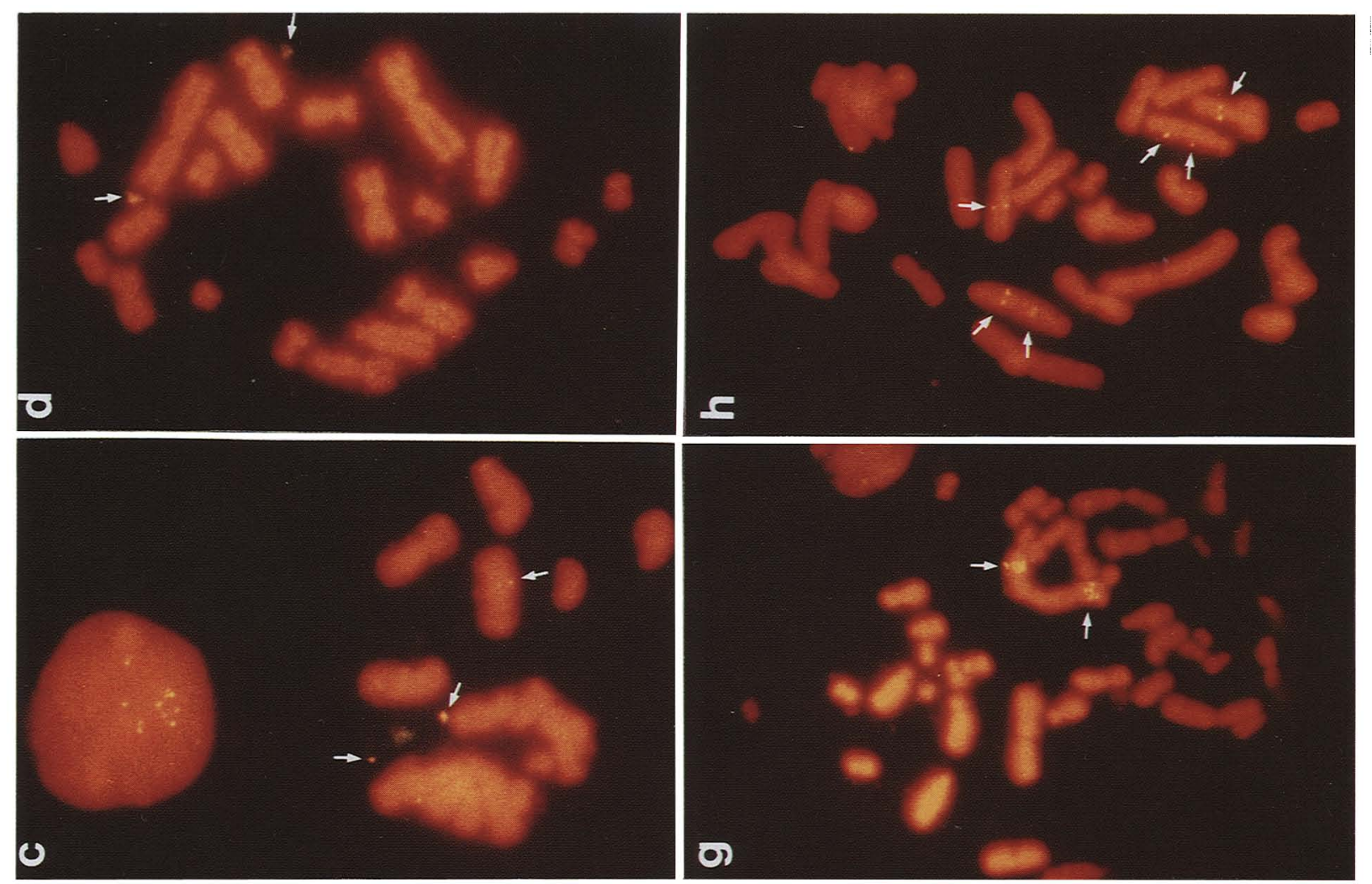

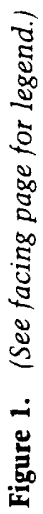
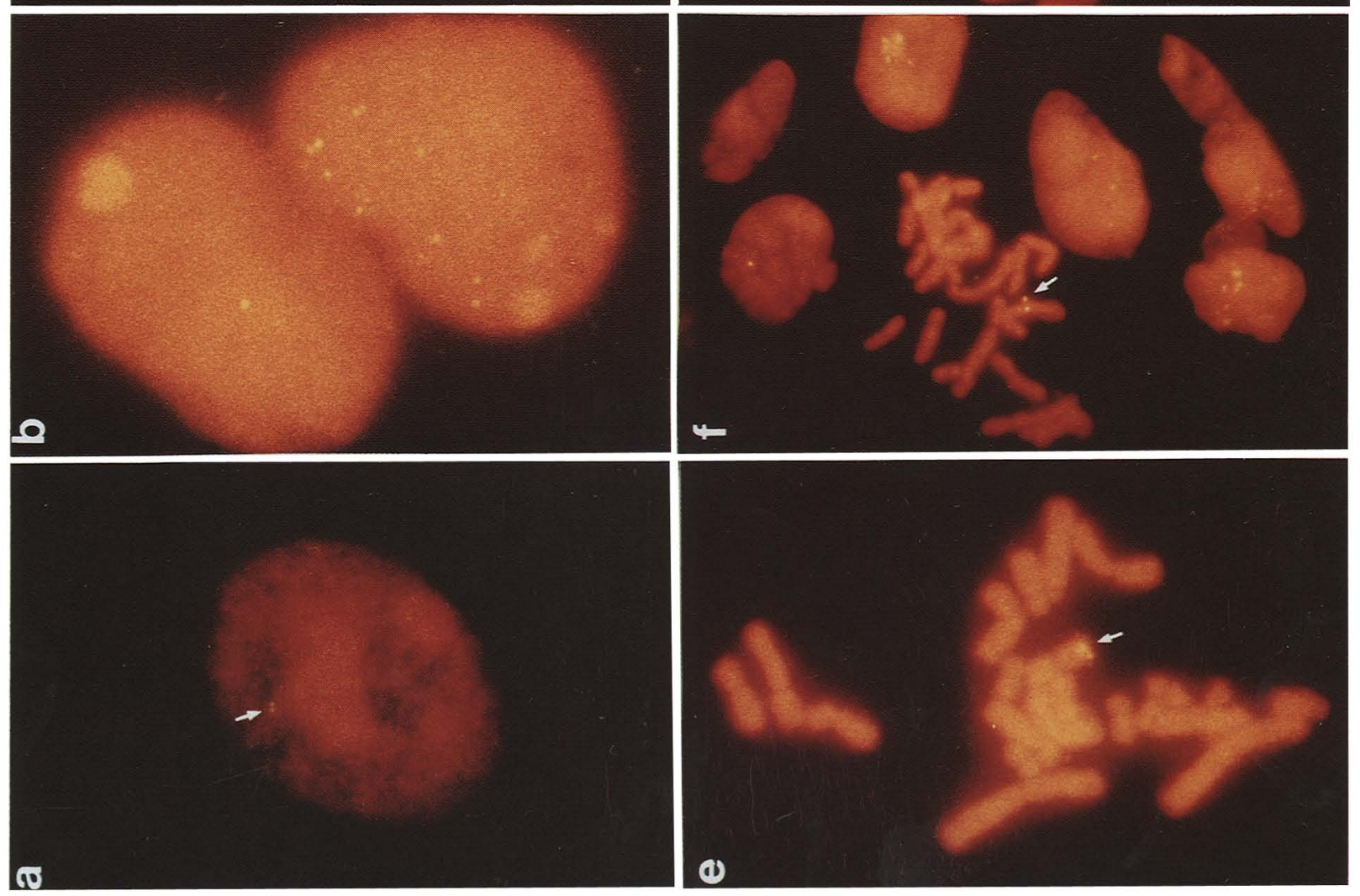

162

GENES \& DEVELOPMENT 
Table 1. DHFR amplicon distribution eight turine cell doublings post-Mtx selection

\begin{tabular}{|c|c|c|c|c|c|c|c|c|c|}
\hline \multicolumn{5}{|c|}{ Interphase nuclei } & \multicolumn{5}{|c|}{ Metaphase spreads } \\
\hline \multirow[b]{2}{*}{ Clone } & \multirow[b]{2}{*}{ Number } & \multicolumn{3}{|c|}{ Percent with $n$ FISH signals } & \multirow[b]{2}{*}{ Number } & \multicolumn{4}{|c|}{ Percent with hybridization to } \\
\hline & & $n=0$ & $n=1-2$ & $n>3$ & & 0 sites & WT & NWT & SEE \\
\hline UA21 & 64 & 20 & 80 & 0 & 50 & 14 & 86 & 0 & 0 \\
\hline \multicolumn{10}{|c|}{ Class 1: small amplicons } \\
\hline $2 \mathrm{~A}$ & 50 & 7 & 35 & 58 & 4 & 0 & 25 & 0 & 75 \\
\hline $2 \mathrm{~B}$ & 16 & 12 & 38 & 50 & 5 & 40 & 40 & 0 & 20 \\
\hline $2 \mathrm{C}$ & 43 & 14 & 43 & 43 & 4 & 0 & 25 & 50 & 50 \\
\hline $2 \Delta$ & 14 & 28 & 42 & 30 & 14 & 14 & 14 & 35 & 42 \\
\hline $\mathrm{C} 3$ & ND & - & - & - & 6 & 33 & 17 & 33 & 17 \\
\hline $\mathrm{Cl} 4$ & 17 & 18 & 18 & 64 & 10 & 60 & 20 & 30 & 40 \\
\hline \multicolumn{10}{|c|}{ Class 2: large amplicons } \\
\hline $\mathrm{Cl}$ & 22 & 18 & 50 & 32 & 13 & 0 & 38 & 85 & 0 \\
\hline $\mathrm{C} 5$ & 28 & 29 & 36 & 35 & 13 & 0 & 31 & 77 & 0 \\
\hline $\mathrm{C} 16$ & 11 & 0 & 55 & 45 & 6 & 0 & 50 & 50 & 0 \\
\hline
\end{tabular}

DHFR FISH signals were counted in interphase cells, and the locations and sizes of the amplicons were determined in metaphase preparations such as those shown in Fig. 1. The 50 UA21 metaphases analyzed here were prepared under identical conditions to those used for the Mtx-resistant cells. Many non-wild-type (NWT) chromosomes may be derivatives of the wild-type (WT) chromosome. Percentages exceeding 100 exist in some cases because individual cells displayed more than one site of hybridization. Class 1 clones contain small extrachromosomal elements (SEE) and small amplicons (see Fig. 1c, d, g); class 2 clones contain large amplicons (Fig. 1h). (ND) Not determined.

one cell contained small extrachromosomal elements while the other contained a single site of hybridization at the end of a metacentric chromosome. The cells in Figure $1, f$ and $g$, represent another example of diverse amplicon locations in a single subclone; other cells in this same subclone manifested extrachromosomal signals.

Extrachromosomal signals were observed in $17-75 \%$ of the metaphases obtained from subclones with small amplicons (Table 1). No extrachromosomal structures were observed in the 50 metaphases from parental UA21 cells prepared under identical conditions or the $\sim 1000$ UA21 metaphases prepared from mass cultures (B. Windle, Y. Yin, and G.M. Wahl, unpubl.). The extrachromosomal signals represent true hybridization to DNA because the yellowish fluorescence of the probe was surrounded by a red halo generated by the propidium iodide counterstain. Structures with similar characteristics to those designated as extrachromosomal elements in these studies were routinely observed in cell lines known, by other criteria, to contain solely extrachromosomal amplicons (Y. Yin and G.M. Wahl, unpubl.).

The amplicons were large in the second class comprising three clones, and there was no evidence of the small extrachromosomal elements described above. The FISH signals in metaphase spreads were widely spaced (Fig. lh). Ring or rod structures containing widely and regularly spaced amplicons and lacking obvious centromeric constrictions were observed in several metaphases (data not shown). In many cases, the spacing between FISH signals was similar to the distance between the endogenous $D H F R$ gene and the adjacent telomere on the long arm of chromosome $\mathrm{Z} 2$. This observation suggests that the large amplicon in this second class of clones consists of all sequences distal to the DHFR gene.

\section{A different distribution of amplicons is observed 30-35 cell doublings postselection}

Previous studies suggested that small extrachromosomal elements of the type described above represent transient intermediates in the amplification process and are prone to integrate in CHO cells (for references, see Wahl 1989; Ruiz and Wahl 1990). The following experiments investigate this issue and the molecular mechanisms that generate unstable amplicons. Since all of the cells in each colony detected at eight to nine cell doublings were required for cytogenetic analysis, a second selection was performed and six independently isolated single-cell clones with $D H F R$ gene amplification were obtained. Each clone was expanded to $\sim 10^{7}$ cells (i.e., $\sim 25$ cell doublings) to obtain sufficient material for additional analyses.

The heterogeneity in the number of sites of DHFR hybridization detected in the experiments described

Figure 1. DHFR gene distribution in Mtx-resistant cells eight to nine cell doublings postselection UA21 cells were selected to resist Mtx, and metaphase spreads were prepared from 10 independently derived clones containing 300-400 cells as described in Materials and methods. Shown are representative interphase and metaphase FISH patterns obtained from UA21 (a) and the following Mtxresistant clones: $\mathrm{C} 5(b) ; \mathrm{C} 3(c) ; 2 \mathrm{C}(d, e) ; 2 \Delta(f, g) ;$ and $\mathrm{Cl}(h)$. A quantitative summary of the results is shown in Table 1 . The arrows indicate bona fide FISH signals (yellowish fluorescence over red propidium iodide stained DNA). Probe: $D H F R$ cosmid c400-30. 
above predicts that most amplification events should result in substantial intercellular differences in the number of functional DHFR genes. Flow microfluorimetry with fluoresceinated Mtx (F-Mtx), a tight binding, and specific inhibitor DHFR (Kaufman et al. 1978; Gaudray et al. 1986) revealed substantial heterogeneity of $D H F R$ expression in all six cell populations derived from the expansion of the respective parent single-cell clones (for one example, see Fig. 2A; P followed by the number of the parental clone designates such populations). Fluorescence-activated cell sorting (FACS) revealed a 30-fold difference in DHFR gene copy number between cells exhibiting the lowest and highest $10 \%$ of DHFR expression

A.
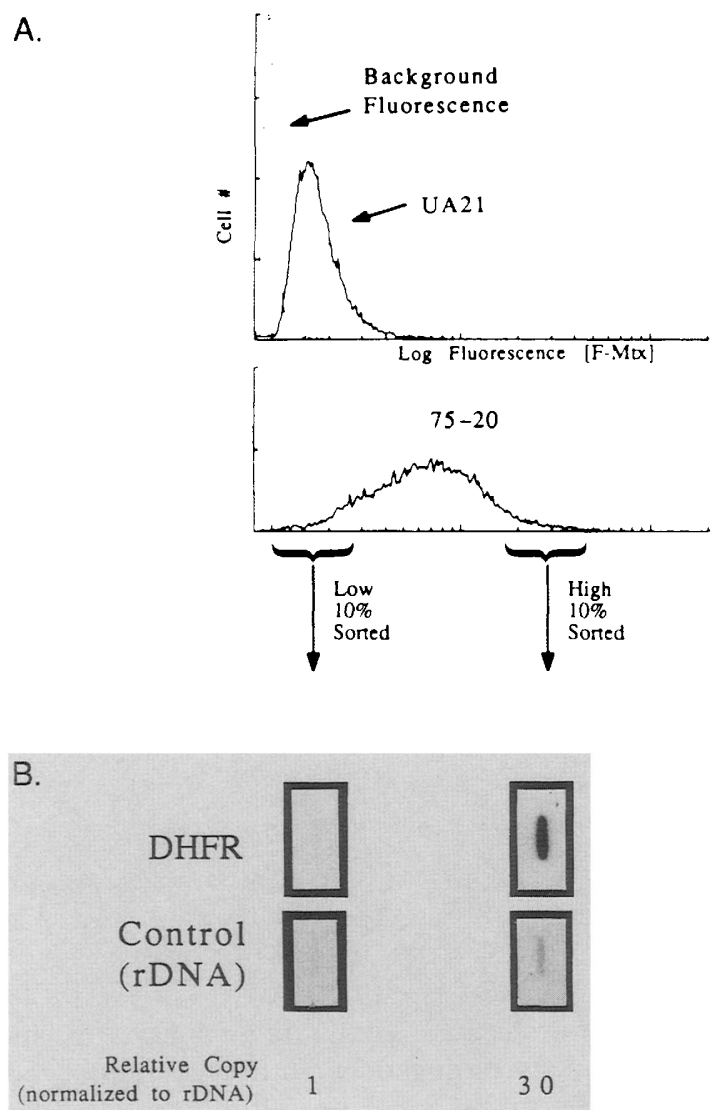

Figure 2. Heterogeneous $D H F R$ gene copy number in cells $\sim 25$ cell doublings postselection. $(A)$ Each of six clones isolated after a single-step Mtx selection, shown to contain amplified DHFR genes, was analyzed for the DHFR content of individual cells $\sim 25$ cell doublings postselection using the F-Mtx staining and FACS protocol described in Materials and methods. Shown are the fluorescence profiles of DG44 (DHFR", designated "background fluorescence"), UA21 (one DHFR copy), and one typical Mtx-resistant cell population (P75-20). (B) P75-20 cells exhibiting the highest and lowest $10 \%$ of F-Mtx binding were isolated for quantitation of relative $D H F R$ gene copy number (see Materials and methods). After hybridization with a DHFR-specific probe, the blot was stripped of bound probe and rehybridized with a rDNA clone (p1 la-2) to provide an internal hybridization standard. The DHFR and rDNA hybridization signals are shown, along with the relative numbers of $D H F R$ copies in the two subpopulations.
(Fig. 2B). Similar results were obtained for populations derived from the other five independently isolated clones (data not shown).

FISH was used to determine the localization of DHFR amplicons 30-35 cell doublings postselection. In contrast to the results seen at eight to nine cell doublings postselection, only $1-2 \%$ of the cells analyzed at $30-35$ cell doublings contained extrachromosomal elements (4/ 390 and 2/100 metaphases of P75-20 and P75-45, respectively; Fig. 3B,C). Approximately $98 \%$ of metaphases displayed intrachromosomal hybridization in clustered amplicons (Fig. 3D,E), The low incidence of extrachromosomal amplicons was not due to the detection sensitivity since the single copy signal in UA21 cells was detected in $99 \%$ of metaphases (Fig. 3A). None of the clones analyzed from the second selection contained the large amplicons detected eight to nine cell doublings postselection. This probably derives from the small sample size since identical selection and propagation conditions were utilized in both selections.

Chromosomally amplified sequences were often observed $(\sim 20 \%$ of the cells in P75-20) at the end of a small metacentric chromosome (Fig. 3D). Quinacrine (Q)banding revealed that this chromosome is a $\mathrm{Z} 2$ chromosome broken at the approximate position of the $D H F R$ locus with a cluster of DHFR genes attached to the end (see chromosomes and nomograms in Fig. 3F). We also detected cells in P75-20 and P75-45, in which the amplified sequences localized to a dicentric chromosome similar to that shown in Figure $1 \mathrm{~g}$ and to multiple chromosomes within a single cell, some of which were clearly not related to $\mathrm{Z} 2$ (see Fig. 3E). Since other studies have described chromosomes with amplified DHFR genes bearing striking similarity to those described here (e.g., Biedler 1982; Trask and Hamlin 1989|, such structures must represent the most common types of cytogenetic products generated by amplification of the CHO DHFR gene in both hemizygous and diploid $\mathrm{CHO}$ cells.

Previous studies have suggested that chromosomal amplicons might be unstable and capable of generating copy number heterogeneity (e.g., see Saito et al. 1989). We tested this possibility by isolating six subclones from P75-20 (referred to as P75-20S5 to P75-20S10), which contained the major classes of chromosomally amplified $D H F R$ genes. The amplified DHFR genes in three subclones were contained in a structure similar to that shown in Figure 3D, one subclone contained a dicentric chromosome similar to that shown in Figure $1 \mathrm{~g}$, and two subclones had derivative $\mathrm{Z} 2$ chromosomes not yet characterized completely but clearly different from each other (see Table 1; data not shown). Each subclone was cultured for 25 cell doublings, and the resulting populations were analyzed for $D H F R$ copy number heterogeneity. For any of the subclones, there was a maximum 1.2fold difference in DHFR copy number between cells expressing the highest and lowest amounts of $D H F R$ enzyme activity. It is significant that cells containing amplified genes within a dicentric chromosome did not generate copy number heterogeneity even though such chromosomes could generate cytogenetic variants, pre- 

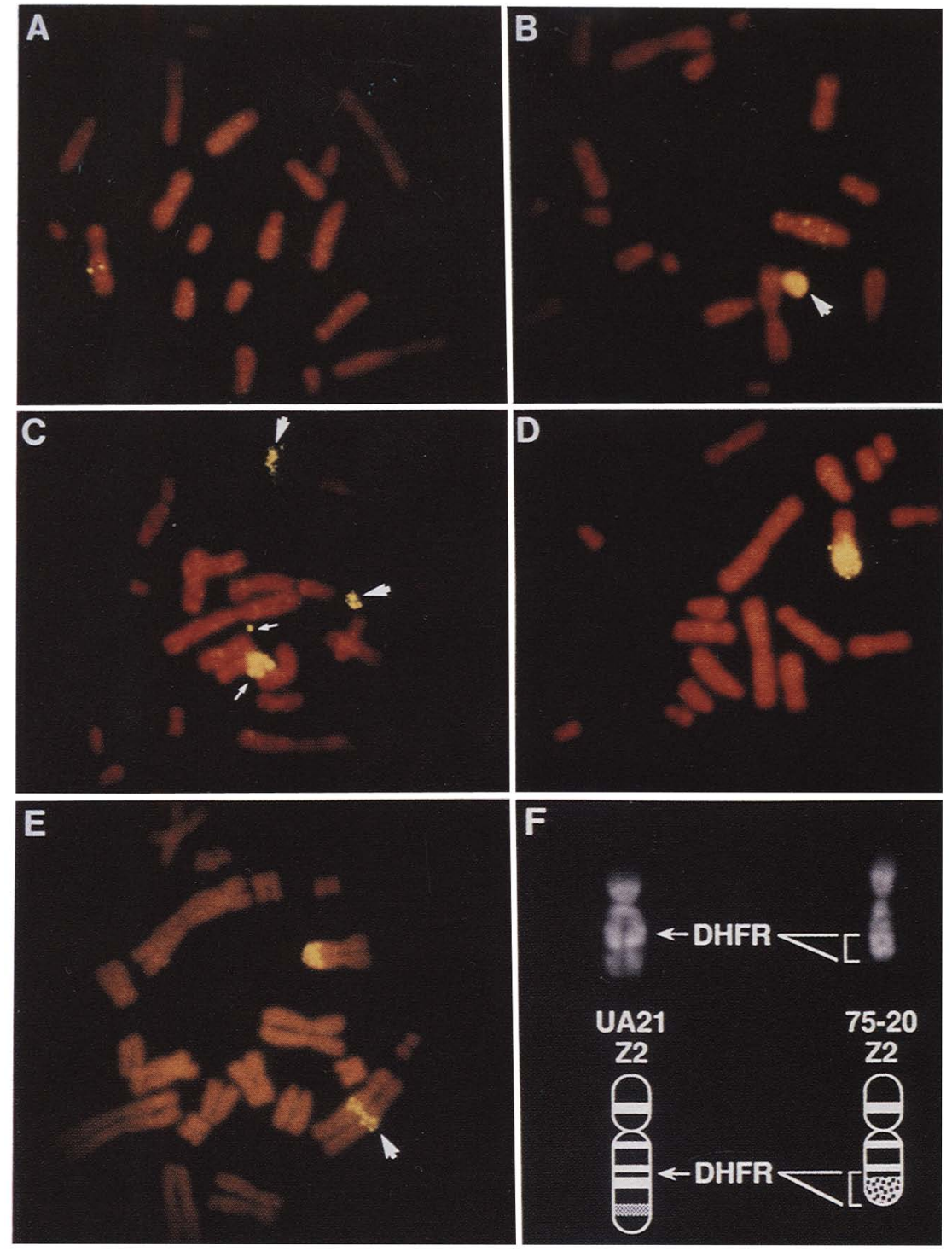

Figure 3. Localization of DHFR amplicons to extrachromosomal and chromosomal structures at $30-35$ cell doublings postselection. Shown are FISH patterns obtained with DHFR cosmid probe c400-30 and metaphase chromosomes from UA21 or Mtx-resistant cell populations $\{\sim 300$ metaphases per Mtx-resistant cell population: see Materials and methods). The efficiency of detecting the single DHFR gene in UA21 cells was $99 \%$ in metaphase spreads prepared under standard conditions. (A) UA21. (B) A cell from $\mathrm{P} 75-20$; (arrow) a large extrachromosomal structure containing multiple DHFR amplicons. $(C)$ A cell from P75-45: (arrows) extrachromosomal $D H F R$ structures of various sizes. $(D, E, F)$ Metaphases from cells of P75-20. (D) The DHFR amplicons are at the end of a broken $\mathrm{Z} 2$ chromosome. $(E)$ DHFR amplicons localize to both a modified chromosome 1 (arrow) and the end of a broken Z2 chromosome. (F) The Z2 chromosomes from UA21 (left) and from a cell of P75-20 (right) that contained amplified DHFR sequences at the end of a metacentric chromosome as shown in $D$ were stained with quinacrine to obtain $Q$ bands. The nomogram of each chromosome is shown, along with the site or region of DHFR hybridization on each chromosome. sumably by bridge-breakage fusion cycles (data not shown; see Kaufman et al. 1983; McClintock 1984; Ruiz and Wahl 1990). The minimal difference in copy number observed in this experiment is within the precision of the assay and is insignificant by comparison with the 30-fold copy number difference observed in the original populations propagated under identical conditions. These results demonstrate that copy number heterogeneity and diversity of amplicon localization were generated by intermediates that predated the formation of the stable chromosomal amplicons detected at 30-35 cell doublings.

\section{Cells with deletion of DHFR sequences from the amplification target can be isolated from each Mtx-resistant population}

Since the small chromosomal amplicons are stable in this system, it is likely that, as in other examples, the small extrachromosomal elements prevalent in such clones at early times engender both copy number and amplicon location heterogeneity (for references, see Wahl 1989). The following studies investigate whether deletion of chromosomal sequences is involved in the generation of extrachromosomal elements as proposed previously (Carroll et al. 1988; Hunt et al. 1990; Ruiz and Wahl 1990). To obtain sufficient material for analysis, the studies were performed 30-35 cell doublings postselection.

If deletion produced the extrachromosomal elements shown in Figures 1 and 3, then growth of cells under nonselective conditions should produce a subpopulation lacking all DHFR genes as a consequence of the random loss of acentric amplicons at mitosis. Since very few cells had solely extrachromosomal elements 30-35 cell doublings postselection, the frequency of obtaining cells devoid of $D H F R$ genes after nonselective growth was expected to be low. Consequently, to make a sensitive as- 
sessment of whether cells with DHFR deletion exist at $30-35$ cell doublings postselection, we implemented the following enrichment and detection strategy. Each of the six independently derived populations with amplified $D H F R$ genes was grown without selection for 10 cell doublings to allow for random segregation and loss of unstable DHFR amplicons. The cells were then stained with F-Mtx, and cells with little or no DHFR expression were isolated using the FACS. This procedure enriched for putative null cells by $\sim 50$-fold. Individual cells containing DHFR deletions were obtained in either of two ways. First, the sorted cells were subdivided further by single-cell cloning. Alternatively, each sorted subpopulation was exposed to a suicide selection procedure that kills cells expressing as few as one DHFR gene through the DHFR-dependent conversion of $\left[{ }^{3} \mathrm{H}\right]$ uridine to $\left[{ }^{3} \mathrm{H}\right]$ thymidine (see Materials and methods). The subclones isolated using both protocols were then analyzed by polymerase chain reaction (PCR) and Southern blotting to determine whether the absence of $D H F R$ expression derived from $D H F R$ gene deletion.

Figure 4A shows a typical PCR analysis of a single-cell subclone $(20 \Delta 1)$, isolated from P75-20 by cell sorting only, which contained no detectable DHFR activity as measured by F-Mtx binding. Each PCR reaction included primers specific for the 5' region of the DHFR gene and for the endogenous thymidine kinase $(T K)$ gene to provide an internal positive control for reaction efficiency. This subclone generated no DHFR-specific PCR product while substantial PCR amplification of the TK sequence was obtained. A parallel reaction that employed UA21 cells generated PCR products of the sizes expected to be generated from the DHFR and TK genes. No DHFR signal was obtained from the controls that lacked DNA or from DG44 cells that contain a double deletion of the DHFR gene (Urlaub et al. 1986).

The DHFR deletion isolation strategy was employed for each of the six populations containing amplified $D H F R$ genes, and each proved to contain cells with a deletion of the DHFR locus. To confirm the PCR results, the clones shown by PCR to have deleted the DHFR gene were expanded for analysis by Southern blot hybridization. Hybridization with a DHFR-specific probe produced intense bands with DNA isolated from UA21 cells, but no hybridization above background was detected in any of the deletion clones (Fig. 4B).

The FACS-suicide selection procedure was used in conjunction with PCR and Southern blot analysis to quantitate the frequency at which cells with DHFR deletion could be obtained from the parental UA21 cells and from each of the six Mtx-resistant cell populations described above. Table 2 shows that the frequency of cells with DHFR deletion ranged from $1.3 \times 10^{-4}$ to $1.8 \times 10^{-3}$. In contrast, no deletions were detected among $4 \times 10^{6}$ UA21 cells grown under the same conditions. Thus, the frequency of obtaining DHFR deletion mutants is at least 500 - to 10,000 -fold higher in cells known to resist Mtx by DHFR gene amplification than in the parental UA21 cells. These data demonstrate that some cells with DHFR gene deletion exist in each of

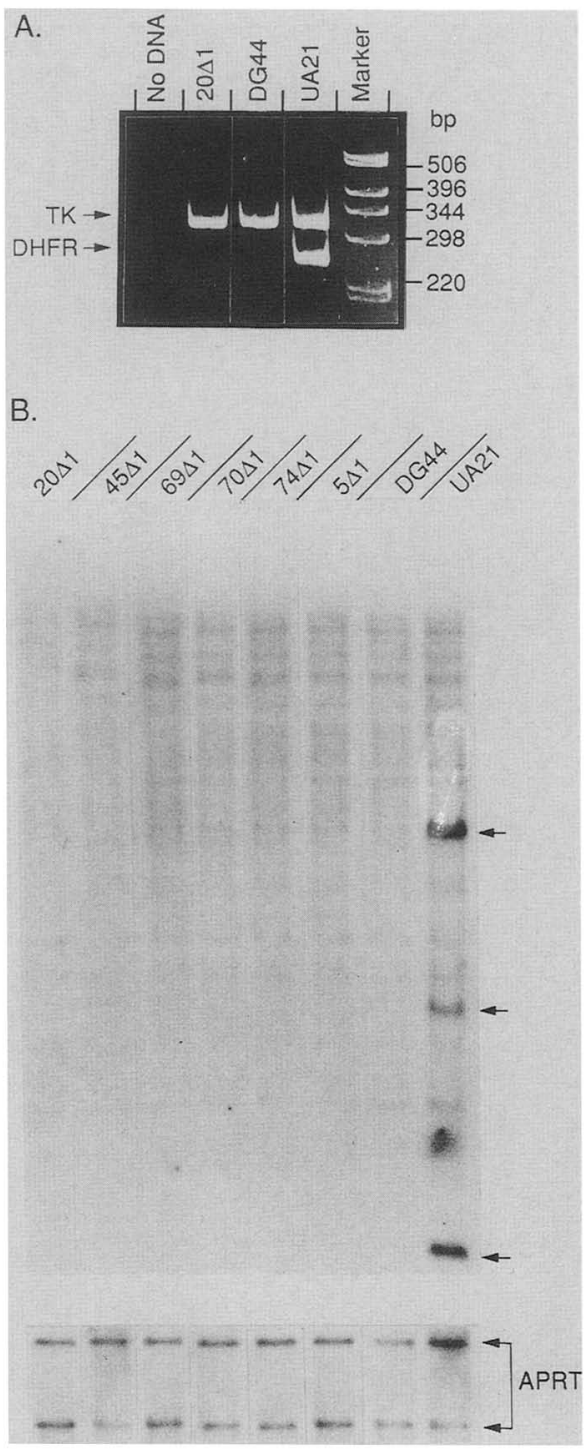

Figure 4. DHFR deletion mutants detected by PCR and Southern blot analyses after nonselective growth of Mtx-resistant cell populations. Cells from Mtx-resistant cell line 75-20 were grown for 10 cell doublings in medium that does not require DHFR for survival. Single cells exhibiting the lowest $2 \%$ of fluorescence were obtained by preparative FACS (see Materials and methods) and expanded into mass culture, and the presence of DHFR genes was assessed by both PCR and Southern blotting. (A) PCR of subclone $20 \Delta 1$ (derived from $75-20$ cells). Each reaction contained primers for the DHFR gene and for the $T K$ gene as a positive control. Negative controls included a reaction with primers, but without added cellular DNA, and cellular DNA from a mutant lacking both copies of the DHFR gene /cell line DG44). (B) Southern blot analysis of DNA isolated from putative deletion mutants identified by PCR. DNA $(\sim 40 \mu \mathrm{g})$ from putative deletion mutants obtained from each of six independently derived Mtx-resistant mutants was digested with EcoRI, fractionated by agarose gel electrophoresis, and Southern blotted. $D H F R$ sequences (arrows) were detected with a probe derived from the $3^{\prime}$ end of the DHFR gene (which contains some repetitive sequences. The hybridized probe was removed, and the blot was rehybridized with a probe specific for the adenine phosphoribosyl transferase $(A P R T)$ gene as a control for the amount of DNA present in each lane. 
Table 2. DHFR gene deletion frequency in cells with DHFR gene amplification

\begin{tabular}{|c|c|c|}
\hline $\begin{array}{l}\text { Cell } \\
\text { line }\end{array}$ & $\begin{array}{c}\text { Amplicon } \\
\text { location(s) } \\
\text { (extrachromosomal/ } \\
\text { chromosomal) }\end{array}$ & $\begin{array}{l}\text { Deletion } \\
\text { frequency }\end{array}$ \\
\hline DG44 & NA & 1.00 \\
\hline UA21 & NA & $<2.5 \times 10^{-7}$ \\
\hline P75-20 & $\mathrm{E} / \mathrm{C}$ & $4.2 \times 10^{-4}$ \\
\hline P75-45 & $\mathrm{E} / \mathrm{C}$ & $1.7 \times 10^{-3}$ \\
\hline P75-69 & nd & $9.7 \times 10^{-4}$ \\
\hline P75-70 & $\mathrm{E} / \mathrm{C}$ & $1.6 \times 10^{-4}$ \\
\hline P75-74 & ND & $1.3 \times 10^{-4}$ \\
\hline P150-5 & ND & $1.8 \times 10^{-4}$ \\
\hline $75-20 S 5$ & broken $\mathrm{Z} 2$ ter & $<10^{-5}$ \\
\hline $75-20 S 6$ & interstitial $\mathrm{Z} 2$ & $<10^{-5}$ \\
\hline $75-20 S 7$ & dicentric Z2 & $<10^{-5}$ \\
\hline $75-20 S 8$ & broken $\mathrm{Z} 2$ ter & $<10^{-5}$ \\
\hline $75-20 S 9$ & broken $\mathrm{Z} 2$ ter & $<10^{-5}$ \\
\hline $75-20 S 10$ & interstitial Z2 & $<10^{-5}$ \\
\hline
\end{tabular}

The negative selection method developed by Urlaub and Chasin (1980; see Materials and Methods) was used to determine the frequency of cells with DHFR deletion in the indicated cell lines. DG44 is a CHO cell line lacking both DHFR genes, which provides a plating efficiency control. No cells with DHFR deletion were obtained from $4 \times 10^{6}$ UA21 cells. Cell populations derived from the expansion of independently isolated single-cell clones with DHFR gene amplification are designated by the prefix $\mathrm{P}$, followed by the clone number. Cell lines designated 75-20S5, etc., are single-cell clones obtained from population P75-20 and were shown by in situ hybridization to contain chromosomally amplified DHFR genes at the indicated locations. The deletion frequencies were determined by plating $2.5 \times 10^{4}$ to $2.5 \times 10^{5}$ cells per population or subclone. (NA) Not applicable; (E) extrachromosomal elements detected; (C) chromosomally amplified regions detected; (ND) not determined.

these six cell populations descended from independently arising parental cells with $D H F R$ gene amplification.

The detection of cells with deletion of the DHFR gene in a heterogeneous population in which the majority of cells contained chromosomally localized amplified sequences could be explained as a consequence of secondary rearrangements within unstable chromosomal structures. For example, a dicentric chromosome such as that shown in Figure $1 \mathrm{~g}$ could theoretically generate deletions through breakage-fusion-bridge cycles (Kaufman et al. 1983; McClintock 1984; Ruiz and Wahl 1990). We therefore determined whether any of the subclones with chromosomal amplicons produce cells devoid of DHFR sequences. If a particular chromosomal amplicon can generate deletions, the frequency of deletion should be substantially higher in the appropriate subclone than in the mixed population However, Table 2 shows that no subclone generated descendants with $D H F R$ deletion under growth conditions that readily gave rise to cells with deletions in the initial population. These data are consistent with the stability of gene copy number in cells with chromosomally amplified DHFR genes (see above), and they indicate that the event giving rise to the dele- tions must have predated the formation of these stable secondary amplification products.

\section{Chromosome breakage during gene amplification}

Since the deletions observed in each cell line may be the products of the initial DNA rearrangements involved in DHFR gene amplification, some of these deletions were characterized further. We isolated two deletion subclones, $20 \Delta 1$ and $20 \Delta 2$, from P75-20 and identified the $\mathrm{Z} 2$ chromosomes by Q-banding. The Z2 chromosomes in these two clones are quite different from one another (Fig. 5A, columns 3 and 5). The Z2 chromosome of $20 \Delta 1$ has a terminal deletion with a break near the DHFR locus. In contrast, comparison of the wild-type Q-banding pattern of chromosome $\mathrm{Z} 2$ with that found in $20 \Delta 2$ revealed that the latter has a large interstitial deletion that removes a band encompassing the DHFR locus (Fig. 5). Since $20 \Delta 1$ and $20 \Delta 2$ both descended from the same parental cell that generated clone 75-20, these results demonstrate that at least two strikingly different manifestations of a DHFR deletion can be derived from a single initiating event.

The deletions in nine subclones isolated from P75-20 were analyzed by Southern blotting of genomic DNA using cosmid probes containing sequences that flank the $D H F R$ gene. This analysis revealed that although all of the nine subclones lacked the DHFR gene, three contained sequences within $40 \mathrm{~kb}$ of the $5^{\prime}$ end of the DHFR gene (encoded by the cosmid c400-13). One of these three subclones was $20 \Delta 1$. The remaining six subclones, including $20 \Delta 2$, contain no sequences that hybridize with c400-13.

FISH analysis of metaphase chromosomes of $20 \Delta 1$ using a c400-13 probe revealed that a single copy of these sequences remains at the terminus of the broken $\mathrm{Z2}$ chromosome (Fig. 5A, column 4; 100/100 metaphases). The position of the hybridization relative to either the centromere or the telomere of the other arm is approximately the same as that of the DHFR gene in the native Z2 chromosome (see Fig. 5A, column 2; cf. with Fig. le). This confirms the Q-banding analyses of Figures $3 \mathrm{~F}$ and $5 \mathrm{~A}$ in which some $\mathrm{Z2}$ chromosomes in these Mtx-resistant cell populations are broken near the DHFR gene.

The cytogenetic and molecular analyses indicate that sequences between the DHFR gene and cosmid c400-13 are missing in deletion mutant $20 \Delta 1$. We investigated whether the deleted region extends into cosmid c400-13 by determining whether any restriction fragments were missing from c400-13 in clone $20 \Delta 1$. Figure $5 B$ shows that only 5 of the $12 \mathrm{XbaI}$ fragments detected in UA21 DNA are present in $20 \Delta 1$ DNA. Thus, a substantial fraction of this region has been deleted from the $20 \Delta 1$ genome, suggesting that sequences in cosmid c400-13 lie close to or at the end of the broken $\mathrm{Z} 2$ chromosome. Further characterization of the broken chromosome is in progress.

Although sequences within $40 \mathrm{~kb}$ of the DHFR gene reside near or at the terminus of a broken $\mathrm{Z} 2$ chromosome in deletion mutant $20 \Delta 1$, Southern analyses re- 
Figure 5. Characterization of DHFR deletions by cytogenetics, FISH, and Southern blot analyses. $|A|$ The $\mathrm{Z} 2$ chromosome or its derivative was identified in UA21 (column 1), $20 \Delta 1$ (column 3), and $20 \Delta 2$ (column 5) by Q-banding, and each is shown with the corresponding nomogram and the position of the DHFR gene. Metaphase spreads $1>100$ analyzed per cell line) prepared from UA21, 20 1 , and $20 \Delta 2$ were then hybridized with cosmid probe c400-13, which contains sequences $\sim 40 \mathrm{~kb}$ upstream of the $5^{\prime}$ end of the DHFR gene (B. Draper, B. Windle and G. Wahl, unpubl.) or cosmid probe c400-30, which contains the DHFR gene sequences (column 2). (B) DNA ( $\sim 40 \mu \mathrm{g}$ ) from UA21, $20 \Delta \mathrm{l}$, and the 75-20 cell population containing amplified $D H F R$ genes was digested with $X b a \mathrm{I}$, fractionated by agarose gel electrophoresis, Southern-blotted, and hybridized with c400-13. The arrows indicate the bands present in UA21 and 75-20 but absent from $20 \Delta \mathrm{l}$. The hybridization signals in 75-20 represent a sixfold amplification of DHFR. c400-13 contains repetitive sequences that create the diffuse hybridization smear.

vealed the unexpected result that some of the terminal sequences identified by cosmid c $400-13$ are clearly amplified in the $75-20$ population (Fig. 5B). A mechanism relating chromosome breakage to both DNA sequence amplification and deletion is considered in detail below.

\section{Discussion}

Amplification mechanisms are not likely to involve multiple, independent, low-probability recombination events since cells with amplified genes arise spontaneously in tumor cell populations at rates of typically $10^{-4}$ to $10^{-6}$ per cell per cell division (Kempe et al. 1976; Johnston et al. 1983; Capecchi 1989; Tlsty et al. 1989). Nonetheless, our analyses show that very early events involve substantial genetic fluidity, since the descendants of each parental cell manifested diversity in the consequences of amplification at the target site, and the number and cytogenetic locations of the DHFR amplicons. A model is presented below that attempts to limit the number of independent recombination events required to generate amplicon diversity by proposing that the initial amplicons are acentric elements generated by chromosome breakage. According to this model, cytogenetic diversity is created by the random segregation and subsequent integration of such elements and the multiple ways in which the broken chromosomes can be repaired.

It is difficult to account for all of the observations concerning amplification of the CHO DHFR gene presented here and elsewhere (e.g., see Kaufman and Schimke 1981; Biedler 1982; Trask and Hamlin 1989) by any of the currently proposed models. For example, unequal sister chromatid exchange requires multiple independent recombination events to produce the copy number heterogeneity detected in early populations. Since recombination frequencies are typically $10^{-4}$ to $10^{-6} / \mathrm{see}$ Capecchi 1989) and sister strand exchanges do not occur at higher frequencies in chromosomally amplified regions than in unamplifled DNA (Chasin et al. 1982; Cowell 
1982), it is unlikely that this mechanism could generate the amplicon diversity detected at eight to nine cell doublings. Furthermore, this mechanism cannot readily account for the generation of both terminal and interstitial deletions in descendants of the same parental cell. A second proposed mechanism, DNA rereplication (Mariani and Schimke 1984; Schimke et al. 1986), has not been observed in mammalian cells (Hahn et al. 1986) and does not readily account for the frequent deletion of the target gene or the genesis of either small or huge amplicons in independent events. A third mechanism, recombination within a replication intermediate /see Wahl 1989|, does not directly predict chromosome breakage, heterogeneous deletions from a single parental cell, or vast differences in amplicon sizes. Finally, it has been proposed that the initial amplification intermediates are very large, intrachromosomal, and highly unstable, and they decrease in size over time (Saito et al. 1989). This model requires that multiple, typically rare recombination events would have to occur every few cell divisions to account for the observed copy number heterogeneity. Our data do not address the possibility that some of the small chromosomal amplicons detected in clones at 3035 cell doublings could have arisen by such a process. On the other hand, it is difficult to envision how this process could occur at a rate sufficient to generate both small extrachromosomal elements and small intrachromosomal amplicons in each of six clones by eight to nine cell doublings. We favor the interpretation that the two differently sized amplicons detected at this early time represent alternative products of chromosome breakage (see Fig. 6A-C and below).

\section{A model for gene amplification involving chromosome breakage within replication intermediates}

There is no evidence that incontrovertibly excludes any of the existing amplification models, but the difficulties considered above led us to develop an alternative in which chromosome breakage initiates the amplification process. Our data agree with previous cytogenetic studies that led to the suggestion that breakage near the $D H F R$ locus could have occurred as a very early event (see Biedler 1982; Biedler et al. 1988). For example, some cells analyzed eight to nine cell doublings postselection contained a small metacentric chromosome with $D H F R$ sequences positioned at or near one terminus. This is most likely a $\mathrm{Z} 2$ chromosome broken in the vicinity of the $D H F R$ locus since the relative lengths of the two arms and the site of DHFR bybridization were the same as in chromosomes frequently detected in later populations, which were shown by Q-banding to be broken Z2s. Importantly, chromosomes containing amplified regions, including cytogenetically unstable dicentric chromosomes, did not generate similarly broken $\mathrm{Z} 2$ chromosomes at experimentally measurable frequencies.

Stalled replication intermediates might provide the substrates for chromosome breakage. This hypothesis is based on two observations. First, conditions that lead to the accumulation of replication intermediates, such as transient inhibition of DNA replication near the time the target gene is replicated, can markedly increase the frequency of gene amplification (Tlsty et al. 1982; Brown et al. 1983) Second, we observed that sequences left at single-copy level at the terminus of the broken $\mathrm{Z} 2$ chromosome were also present in the amplicons of the Mtxresistant cell population. This suggests that the amplification target contained two copies of such sequences prior to or coincident with the initiating event and that the breakage event was asymmetrical (see Fig. 6A-C).

A particular strength of the asymmetric breakage model is that it provides a simple mechanism for producing the amplicons of diverse size and structure. Figure $6 \mathrm{~A}$ shows that two breaks introduced on opposite sides of a replication bubble produce an amplicon containing all DNA sequences between the break site and the telomere of the same arm. Such large amplicons were detected here and have been described in CAD gene amplification in Syrian hamster cells (Wahl et al. 1983; Giulotto et al. 1986). Asymmetric breakage at three (Fig. 6B) or four sites (Fig. 6C), coupled with appropriate end ligation reactions, will produce circular amplicons and a broken chromosome terminated by sequences homologous to some of those in the amplicon. Circles produced by four breaks/ligations will contain imperfect inverted repeats of the type typically found in mammalian amplicons (Ford and Fried 1986; Saito and Stark 1986; Looney and Hamlin 1987; Passananti et al. 1987; Hyrien et al. 1988; Ruiz and Wahl 1988). The sizes of such extrachromosomal amplicons could easily conform to the majority of amplicon sizes detected at the CHO DHFR locus (Looney et al. 1988). However, since some amplicons are probably larger than one replicon (Borst et al. 1987; Looney et al. 1988; Jongsma et al. 1989), their genesis would require simultaneous or sequential breaks in two or more adjacent replication intermediates.

All of the breakage patterns described above produce acentric molecules that contain the target locus. Such molecules should segregate unequally at mitosis to generate a population in which they accumulate in some cells and are lost from others. Unequal segregation provides an extremely simple mechanism for rapidly generating the copy number heterogeneity we observed in every population with amplified $D H F R$ genes. Since cells with as few as four DHFR genes could survive the selective conditions utilized here (B. Windie, Y. Yin, and G.M. Wahl, unpubl.), only two rounds of replication and unequal segregation would be required to generate resistant cells by this mechanism. Larger per cycle increases in copy number would be achieved if the replication of acentric circular molecules were deregulated or occurred by a rolling circle or similar mechanism (e.g., see Stark and Wahl 1984). Continued propagation, particularly under conditions where elevated gene expression confers a selective advantage, would lead to the accumulation of cells with higher levels of amplification. Importantly, the only recombination events required for gene amplification to occur by this mechanism are those that generate the initial break and acentric amplicon. Copy number increases arise "passively" by unequal segregation. 


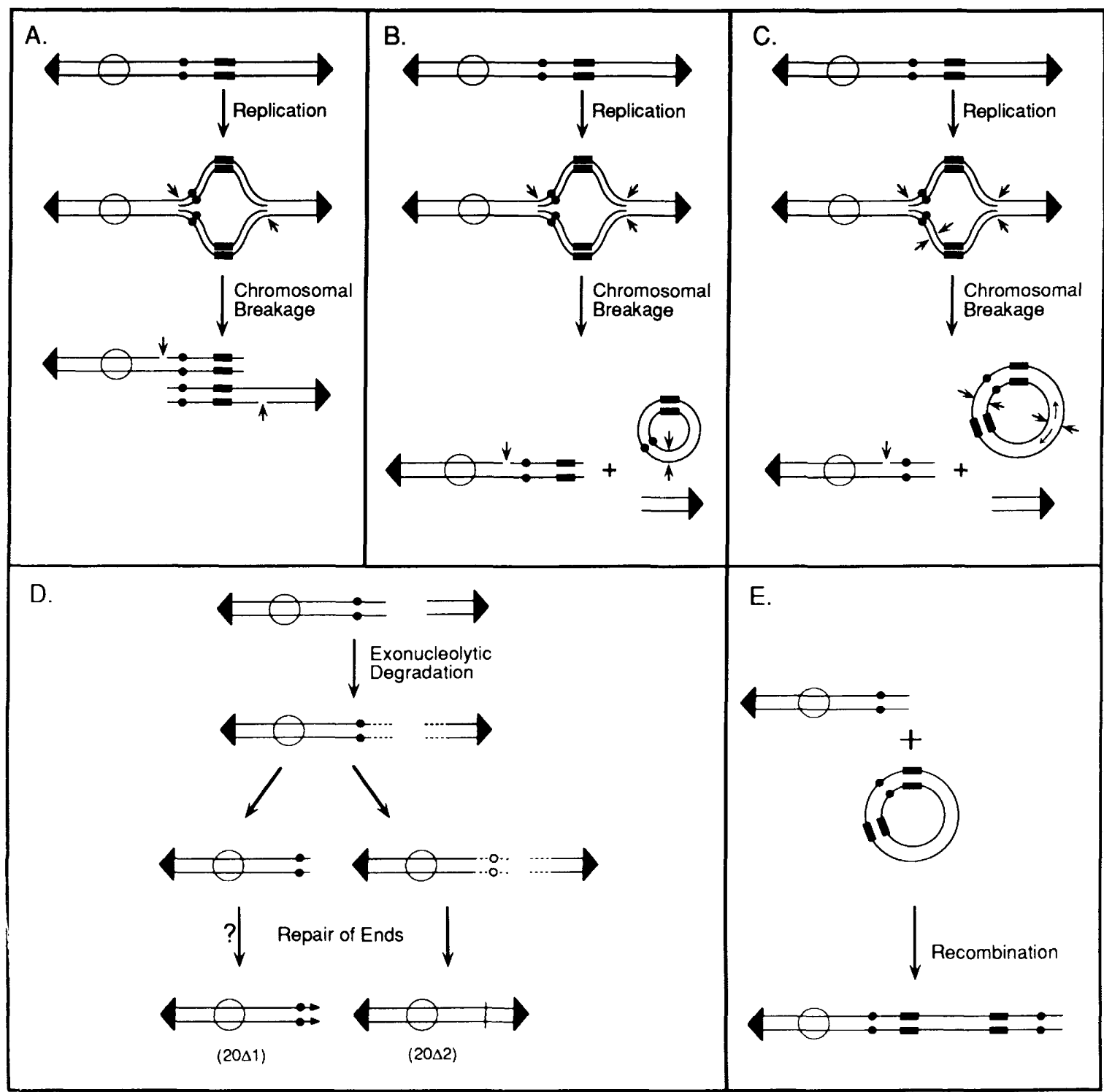

Figure 6. Chromosome breakage model for gene amplification. This model proposes that amplicons are acentric chromosome fragments produced by chromosome breakage. $A-C$ show how asymmetric breakage at two $(A)$, three $(B)$, or four sites $(C)$ creates amplicons of various sizes and configurations. Breakage within a single-replication intermediate is shown for simplicity, but events comprising adjacent replicons may also occur. The large arrowheads indicate break sites. The placement of breaks at the ends of the newly replicated regions is done only for illustration; appropriate asymmetric breaks introduced elsewhere would produce products that are also consistent with our results. $(D)$ Generation of heterogeneous deletions by removal of terminal sequences. The breakage events depicted in $A$ create ends presumably devoid of telomeres. Incomplete replication, or exonucleolytic degradation of such ends, or both, could generate heterogeneous deletions from a common parental structure. Ligation of centric and acentric fragments could

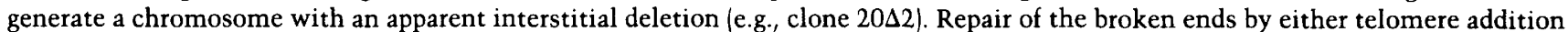

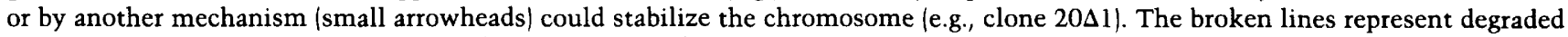
DNA. $(E)$ Targeted integration initiated by free ends. Preferential integration (by homologous or nonhomologous recombination) of acentric structures to the break site is proposed to be initiated by the free ends present in the broken chromosome. The large open circle at the left end of each chromosome indicates the centromere. (Solid rectangle) DHFR gene; (solid circle) sequences detected by probe c $400-13, \sim 40 \mathrm{~kb}$ upstream of the $5^{\prime}$ end of the DHFR gene. The large solid triangles at the ends of the chromosomes represent the native telomeres.

Small extrachromosomal intermediates such as those detected in six to nine clones at eight to nine cell doublings appear to be transient intermediates in the amplification process since they were far more prevalent at early stages $[\sim 40 \%$ of metaphases $(16 / 43)$ at eight to nine cell doublings vs. $1-2 \%$ of metaphases at $30-35$ cell doublings $(6 / 490)]$. This is consistent with a wealth of earlier observations that such elements integrate into chromo- 
somes over time, that this process occurs very rapidly in $\mathrm{CHO}$ cells, and that cells with chromosomally amplified sequences have a growth advantage when the population is passaged under continuous selective pressure (e.g., for more references and further discussion, see Biedler 1982; Wahl 1989; Ruiz and Wahl 1990; Von Hoff et al. 1990).

A second property of the asymmetric breakage model is that the atelomeric chromosomal ends generated by this process provide substrates for recombination events (Fig. 6E). Integration of amplicons at the unprotected ends of the centric or acentric $\mathrm{Z} 2$ fragment, followed by joining of the fragments in various combinations, could readily explain the frequent and rapid localization of amplicons to derivative $\mathrm{Z} 2$ chromosomes (also see Biedler 1982; Nunberg et al. 1978; Trask and Hamlin 1989; B. Windle and G.M. Wahl, in prep.). Precedent for preferred integration at broken chromosome ends has been obtained in Saccharomyces cerevisiae (Szostak et al. 1983; Haber and Thorburn 1984). Since the probability of targeted insertion in mammalian cells increases with the length of homology (Thomas and Capecchi 1987; Capecchi 1989), asymmetric breakage could facilitate targeted integration considerably because a region of homology equivalent in size to the amplicon (i.e., $100 \mathrm{~kb}$ to $>1000$ $\mathrm{kb}$ ) could be left at the terminus of the broken $\mathrm{Z} 2$ chromosome. Other studies strengthen the idea that targeting of amplicons to sites of chromosome breakage may be of general importance in mammalian cells (Biedler et al. 1988; Riva et al. 1989).

The studies reported here and elsewhere reveal that the target locus is often deleted in cells that have undergone gene amplification (Carroll et al. 1988; Hunt et al. 1990; Ruiz and Wahl 1990). Surprisingly, the experiments reported here reveal that a single initiating event can generate deletions with heterogeneous endpoints and cytogenetic characteristics. Asymmetric breakage could produce heterogeneous deletions in independently derived cells or in descendants of the same parent in at least two ways. First, appropriate breaks could remove the (replicated) target gene from the chromosome as an extrachromosomal amplicon. Loss of this amplicon by random segregation would produce a cell with a deletion of these sequences. Second, all of the breakage events shown in Figure 6, A-C, generate a centric chromosome and an acentric fragment that each have one atelomeric end (Fig. 6D). These ends are subject to progressive shortening because they cannot be replicated completely $(\mathrm{Za}$ kian 1989) or because they are substrates for nucleolytic attack. Stochastic resection of the broken chromosome ends should generate heterogeneous deletion endpoints. Replication of the acentric arm, followed by random segregation, should lead to its accumulation in some cells and absence from others. Deletion cell line $20 \Delta \mathrm{l}$ appears to have been cloned from a cell that lost the acentric $\mathrm{arm}$; in deletion clone $20 \Delta 2$, the acentric arm appears to have rejoined with the centric $\mathrm{Z} 2$ fragment to generate a $\mathrm{Z} 2$ chromosome with an interstitial deletion. The translocation of the acentric arm to chromosomes other than $\mathrm{Z} 2$ as a result of $D H F R$ gene amplification has been observed previously (Biedler 1982; Flintoff et al. 1984). The reasons why terminal sequences of the centric arm in $20 \Delta 1$ are preserved are unknown but could involve telomere addition (see Zakian 1989) or extremely slow resection, as observed in Drosophila (Levis 1989). Recent analyses of deletions in the globin locus suggest that breakage, resection, and fusion may be a general mechanism of deletion formation (Henthorn et al. 1990).

An independent in situ hybridization analysis of $\mathrm{CHO}$ $D H F R$ gene amplification indicated that sequences in the DHFR locus were preserved at single-copy level at the native position (Trask and Hamlin 1989). The investigators interpreted the data as evidence against the occurrence of sequence deletion during DHFR gene amplification. However, the probe they employed consisted of cosmids spanning $273 \mathrm{~kb}$ of the DHFR locus. The use of probe encompassing such a large region would have prevented the detection of a deletion of part of the sequences contained within it. Frequent retention of part of the sequences within this $273-\mathrm{kb}$ region is entirely consistent with results presented here and with the predictions of the asymmetric breakage model.

Since many loci replicate at similar times (e.g., see Hatton et al. 1988), we speculate that replication intermediates of unlinked loci might accumulate under suboptimal growth conditions, and resolution of such intermediates by the events depicted in Figure 6 could lead to the production of multiple amplifications, deletions, or other large-scale genetic alterations in a single cell. Such a mechanism could explain the unexpectedly high frequency of coamplification of unlinked genes (Giulotto et al. 1987; Rice et al. 1987) and contribute to the genesis of multiple chromosomal alterations in cancer cells (e.g., see Vogelstein et al. 1989).

\section{Materials and methods}

Cell lines and Mtx selection

The CHO cell line UA21 (Urlaub et al. 1986), which is hemizygous for the DHFR gene, was used in the Mtx selections. The CHO cell line DG44 (Urlaub et al. 1986), which is phenotypically $D H F R^{-}$due to a double deletion of the DHFR gene, was used in these experiments as a null control. Mtx-resistant mutants of UA21 were selected in Dulbecco's minimal essential medium (DMEM) with nonessential amino acids, $10 \%$ dialyzed fetal bovine serum (dFBS) and $75 \mathrm{nM} \mathrm{Mtx}\left(5 \times \mathrm{LD}_{50}\right)$ to $150 \mathrm{nM}$ $\operatorname{Mtx}\left(10 \times L_{50}\right)$. An inoculum of 100 cells was expanded to either $10^{5}-10^{6}$ or $10^{7}$ cells for analyses at $8-9$ or at $\sim 25-35$ cell doublings postselection, respectively. This procedure was employed to give the highest probability of analyzing newly occurring amplification events that were independent of one another. Since the frequency of cells with $D H F R$ gene amplification was $10^{-5}$ to $10^{-6}$ in these experiments, most amplification events should have occurred within the seven cell-doubling window between $10^{5}$ and $10^{7}$ cells. More than one step of selection was avoided to minimize the isolation of cells containing secondary rearrangements that could obscure the nature of the initial amplification event. Nomenclature for the mutants is divided into two numbers: The first refers to the Mtx concentration used for selection, and the second identifies the isolate as a specific single-cell clone. 


\section{DHFR DNA detection and quantitation}

The DHFR copy number for each cell line was determined by DNA slot blot hybridization, as described by Meinkoth and Wahl (1984), using a slot blot apparatus (Shleicher \& Schuell, Keene, NH). DNA was extracted by incubation of cells with $1 \%$ SDS and $100 \mathrm{mg} / \mathrm{ml}$ proteinase $\mathrm{K}$ at $37^{\circ} \mathrm{C}$ for $4 \mathrm{hr}$, followed by phenol extraction and ethanol precipitation. Genomic DNA / 1 $\mu \mathrm{g}$ ) was blotted and hybridized with a nick-translated BamHI fragment specific for exon 6 of the CHO DHFR gene /Carothers et al. 1983). After stringent washing the slot blot was exposed to film, and the amount of hybridization was quantified by scanning densitometry. The probe was eluted by boiling the membranes in $0.1 \times \mathrm{SSPE} / 0.1 \% \mathrm{SDS}$, and a probe specific for ribosomal DNA (plasmid pl1a-2; Wahl et al. 1983) was hybridized to determine the relative amounts of hybridizable DNA applied.

The PCR conditions were as follows: $500 \mathrm{ng}$ of the two CHO DHFR primers 5 '-GGAAGAACCGGCTCAGAACCGCTTGTCTCC- ${ }^{\prime}$ and $5^{\prime}$-GAGGCCACGCCTCAACAAGCCTAGCATCCT-3'; $50 \mathrm{ng}$ of the two CHO TK primers 5'-AAGAAGTCCTCGGTACAGCCTGCTGGGCCA-3' and 5'-AAGCAGGCGCTGCTCTAGTCTGGGCTAAA- $3^{\prime}$ in the buffer described by Kim and Smithies (1988). DNA from $\sim 500$ cells per reaction was prepared as described by Kim and Smithies (1988). Temperature cycling in a programmable cyclic reactor (Ericomp, San Diego, CA) was as follows: 35 cycles of $1 \mathrm{~min}$ at $92^{\circ} \mathrm{C}$ /denaturation), $1 \mathrm{~min}$ at $60^{\circ} \mathrm{C}$ (annealing), and $3 \mathrm{~min}$ at $72^{\circ} \mathrm{C}$ (polymerization). The PCR products were analyzed by polyacrylamide gel electrophoresis and ethidium bromide staining.

Southern blot analysis was performed as described by Meinkoth and Wahl (1984) with DNA transferred to nitrocellulose. DNA was digested with the appropriate restriction enzyme, and $40 \mu \mathrm{g}$ was loaded per lane of an $0.8 \%$ agarose gel. Cosmid probe hybridizations were performed with nick-translated DNA from which repeats were removed by prehybridization with CHO DNA to Cot 1 .

The cosmid c400-30, which encodes the entire DHFR gene, was isolated from a pWE 16 cosmid library prepared from cell line CHOC400 (Milbrandt et al. 1981) using the probe for exon 6 of DHFR mentioned earlier. The cosmid c400-13 was isolated from the same library using the DHFR PCR primers as probes.

\section{FACS analysis}

Cells were stained with F-Mtx (Molecular Probes), as described by Gaudray et al. (1986), analyzed by FACS, and sorted for either DHFR quantitation (Ruiz and Wahl 1988) or DHFR mutant isolation.

\section{FISH}

For analyses at eight to nine cell doublings postselection, the number of cells in each colony were counted, and the colonies were trypsinized and seeded into chamber slides (Nunc) and allowed to attach in the absence of Mtx for 18-24 hr. The cells were treated with colcemid $(10 \mu \mathrm{g} / \mathrm{ml})$ for $1 \mathrm{hr}$ at $37^{\circ} \mathrm{C}$, followed by hypotonic solution $(2 \mathrm{ml}$ of $75 \mathrm{~mm} \mathrm{KCl})$ for $15 \mathrm{~min}$ at $25^{\circ} \mathrm{C}$. The $\mathrm{KCl}$ was aspirated, freshly made fixative $(3: 1 \mathrm{MeOH} /$ HOAc) was added gingerly to minimize removal of attached cells, and incubation in fixative continued for $30 \mathrm{~min}$ at $4^{\circ} \mathrm{C}$. The upper chamber was removed, and the slides were passed briefly over a flame to engender formation of metaphase spreads.

Metaphase chromosome spreads from later-stage cells were prepared as described by Carroll et al. (1988). The conditions for hybridization were as published (Pinkel et al. 1988). Cosmid probes were labeled with biotin-11-dUTP (Enzo) in a nick-translation buffer (Enzo) containing all four NTPs (Pharmacia). Probe (20 ng) was mixed with $10 \mu \mathrm{g}$ of sonicated CHO DNA for each $10-\mu$ l hybridization reaction. Both probes and CHO DNA were $100-500$ bases in size. Fluorescence was detected on a Zeiss fluorescence microscope using a 450 - to 490 -nm wavelength filter with a $100 \times$ planapo objective. Chromosomes were photographed with Kodak Ektachrome ASA 400 slide film. Typically, 300-400 metaphase spreads were analyzed for each cell population, and at least 100 metaphases were examined for each subclone.

Q-banding was performed on metaphase chromosomes according to standard protocols. Fluorescent in situ hybridizations were performed on the same chromosomes following the removal of quinacrine. While this protocol enabled unambiguous conclusions to be made about the location of the hybridization signal on the banded chromosomes upon visualization under the microscope, the hybridization signal was sufficiently compromised by the residual quinacrine fluorescence such that accurate photographic reproduction was not possible. Therefore, data from such experiments are presented as individual hybridization and Q-banding results from different spreads of the same cells.

\section{Detection and isolation of cells with DHFR gene deletion}

Cells were grown in nonselective medium (DMEM, nonessential amino acids, $10 \%$ dFBS, $10 \mathrm{~mm}$ glycine, $30 \mathrm{~mm}$ hypoxanthine, and $3 \mathrm{~mm}$ thymidine) for 10 days to allow segregation of unstable amplicons. The resulting cell population was stained with F-Mtx $(10 \mu \mathrm{M}$; Molecular Probes, Eugene, Oregon; for conditions, see Gaudray et al. 1986), and $2 \%$ of the cells with the lowest fluorescence were collected using the FACS. Approximately $2.5 \times 10^{4}$ cells were isolated and either singlecell-cloned or, for negative selection experiments, plated into a 6-cm dish and grown for $\sim 40 \mathrm{hr}$ to eliminate the F-Mtx from the cells. For negative selection, the plated cells were incubated with fresh medium containing $\left.0.15 \mu \mathrm{M}(8 \mu \mathrm{Ci}) \mid{ }^{3} \mathrm{H}\right) \mathrm{d}$-uridine (New England Nuclear) for $24 \mathrm{hr}$ to select for $\mathrm{DHFR}^{-}$cells as described by Urlaub and Chasin (1980), Cells that resisted the selection and formed colonies were isolated for analysis by PCR and by Southern blot hybridlzstion to determine the fraction with DHFR gene deletion.

\section{Acknowledgments}

G.M.W. dedicates this paper to his father, Alfred Wohl, whose long-standing encouragement and support enabled these studies to come to fruition. We thank Dr. T.C. Hsu for performing the Q-banding, J. Trotter for expert assistance in using the FACS, Drs. B. Trask, D. Pinkel, and J. Ruiz for helpful discussions and assistance with FISH, Drs. L.A. Chasin and G. Urlaub for providing cell lines UA21, DG44, and the probe for the $3^{\prime}$ end of the CHO DHFR gene, and Dr. J. Hamlin for providing cell line CHO C400. The editorial efforts and perceptive comments of Drs. S. Carroll, M. McKeown, and W. Eckhart and the assistance of E. Stevens in preparing this manuscript are highly appreciated. This work was supported by grants to G.M.W. from the National Institutes of Health and the G. Harold and Leila Y. Mathers Charitable Foundation, National Cancer Institute Core grant CA 14195, and a National Cancer Institute postdoctoral fellowship to B.W.

The publication costs of this article were defrayed in part by payment of page charges. This article must therefore be hereby 
marked "advertisement" in accordance with 18 USC section 1734 solely to indicate this fact.

\section{References}

Biedler, J.L. 1982. Evidence for a transient prolonged extrachromosomal existence of amplified DNA sequences in antifolate-resistant, vincristine-resistant, and human neuroblastoma cells. In Gene amplification (ed. R.T. Schimke), pp. 39-45. Cold Spring Harbor Laboratory, Cold Spring Harbor, New York.

Biedler, J.L., T. Chang, T. K.W. Scotto, P.W. Melera, and B.A. Spengler. 1988. Chromosomal organization of amplified genes in multidrug-resistant Chinese hamster cells. Cancer Res. 48: 3179-3187.

Bishop, M.J. 1987. Molecular genetics of cancer. Science 235: 305-311.

Borst, P., A.M. Van Der Bliek, T. Van Der Velde-Koerts, and E. Hes. 1987. Structure of amplified DNA, analyed by pulsed field gradient gel electrophoresis. I. Cell. Biochem. 34: 247258.

Brown, P.C., T.D. Tlsty, and R.T. Schimke. 1983. Enhancement of methotrexate resistance and dihydrofolate reductase gene amplification by treatment of mouse $3 \mathrm{~T} 6$ cells with hydroxyurea. Mol. Cell. Biol. 3: 1091-1107.

Capecchi, M.A. 1989. Altering the genome by homologous recombination. Science 244: 1288-1292.

Carothers, A.M., G. Urlaub, N. Ellis, and L.A. Chasin. 1983. Structure of the dihydrofolate reductase gene in Chinese hamster ovary cells. Nucleic Acids Res. 11: 1997-2012.

Carroll, S.M., M.L. DeRose, P. Gaudray, C.M. Moore, D. Needham-Vandevanter, D.D. Von Hoff, and G.M. Wahl. 1988. Double minute chromosomes can be produced from precursors derived from a chromosomal deletion. Mol. Cell. Biol. 8: $1525-1533$

Chasin, LA, L. Graf, N. Ellis, M. Landzberg, and G. Urlaub. 1982. Gene amplification in dihydrofolate reductasedeficient mutants. In Gene amplification (ed. R.T. Schimke), pp. 161-166. Cold Spring Harbor Laboratory, Cold Spring Harbor, New York.

Cowell, J.K. 1982. Double minutes and homogeneously staining regions: Gene amplification in mammalian cells. Annu. Rev. Genet. 16: 21-59.

Deaven, L.L. and D.F. Peterson. 1973. The chromosomes of $\mathrm{CHO}$, an aneuploid Chinese hamster cell line: G-band, Cband, and autoradiographic analysis. Chromosoma 41: 129144.

Flintoff, W.F., S.V. Davidson, and L. Siminovitch. 1976. Isolation and partial characterization of three methotrexate-resistant phenotypes from Chinese hamster ovary cells. Somatic Cell Genet. 2: 245-261.

Flintoff, W.F., E. Livingston, C. Duff, and R.G. Worton 1984. Moderate-level gene amplification in methotrexate-resistant Chinese hamster ovary cells is accompanied by chromosomal translocation at or near the site of the amplified DHFR gene. Mol. Cell. Biol. 4: 69-76.

Ford, M. and M. Fried. 1986. Large inverted duplications are associated with gene amplification. Cell 45: 425-430.

Funanage, V.L. and T.T. Myoda. 1986, Localization of the Chinese hamster dihydrofolate reductase gene to band p23 of chromosome 2. Somatic Cell Mol. Genet. 12: 649-655.

Gaudray, P., J. Trotter, and G.M. Wahl. 1986. Fluorescent methotrexate labeling and flow cytometric analysis of cells containing low levels of dihydrofolate reductase. I. Biol. Chem. 261: 6285-6292.
Giulotto, E., I. Saito, and G.R. Stark. 1986. Structure of DNA formed in the first step of CAD amplification. EMBO $J$. 5: 2115-2121.

Giulotto, E., C. Knights, and G.R. Stark. 1987. Hamster cells with increased rates of DNA amplification. A new phenotype. Cell 48: 837-845.

Haber, J.E. and P.C. Thorburn. 1984. Healing of broken linear dicentric chromosomes in yeast. Genetics 106: 207-226.

Hahn, P., L.N. Kapp, W.F. Morgan, and R.B. Painter. 1988. Chromosomal changes without DNA over-production in hydroxyurea-treated mammalian cells: Implications for gene amplification. Cancer Res. 48: 4607-4612.

Hatton, K.S., V. Dhar, E.H. Brown, M.A. Iqbal, S. Stuart, V.T. Didamo, and C.L. Schildkraut. 1988. Replication program of active and inactive multigene families in mammalian cells. Mol. Cell. Biol. 8: 2149-2158.

Henthorn, P.S., O. Smithies, and D.L. Mager. 1990. Molecular analysis of deletions in the human $\beta$-globin gene cluster: Deletion junctions and locations of breakpoints. Genomics 6: $226-237$.

Hunt, J.D., M. Valentine, and A. Tereba. 1990. Excision of Nmyc from chromosome 2 in human neuroblastoma cells containing amplified N-myc sequences. Mol. Cell. Biol. 10: $823-829$.

Hyrien, O., M. Debatisse, G. Buttin, and B. Robert de Saint Vincent. 1988. The multicopy appearance of a large inverted duplication and the sequence at the inversion joint suggest a new model for gene amplification. EMBO /. 7: 407-417.

Johnston, R.N., S.M. Beverley, and R.T. Schimke. 1983. Rapid spontaneous dihydrofolate reductase gene amplification shown by fluorescence-activated cell sorting. Proc. Natl. Acad. Sci. 80: 3711-3715.

Jongsma, A.P.M, W.A.L. Duiindam, and P. Borst. 1989. DNA content and structure of (double) minutes of a methotrexateresistant cell line. Histochemistry 93: 87-92.

Kaufman, R.J. and R.T. Schimke. 1981. Amplification and loss of dihydrofolate reductase genes in a Chinese hamster ovary cell line. Mol. Cell. Biol. 1: 1069-1076.

Kaufman, R.J., J.R. Bertino, and R.T. Schimke. 1978. Quantitation of dihydrofolate reductase in individual parental and methotrexate-resistant murine cells. I. Biol. Chem. 253:5852-5868.

Kaufman, R.J., P.S. Sharp, and S.A. Latt. 1983. Evolution of chromosomal regions containing transfected and amplified dihydrofolate reductase sequences. Mol. Cell. Biol. 3: 699-711.

Kempe, T.D., E.A. Swyryd, M. Bruist, and G.R. Stark. 1976. Stable mutants of mammalian cells that overproduce the first three enzymes of pyrimidine nucleotide biosynthesis. Cell 8: 541-550.

Kim, H.S. and O. Smithies. 1988. Recombinant fragment assay for gene targeting based on polymerase chain reaction. $\mathrm{Nu}$ cleic Acids Res. 16: 8887-8903.

Levis, R.W. 1989. Viable deletions of a telomere from a Drosophila chromosome. Cell 58: 791-801.

Looney, J.E. and J.L. Hamlin. 1987. Isolation of amplified dihydrofolate reductase domain from methotrexate-resistant Chinese hamster ovary cells. Mol. Cell. Biol. 7: 569-577.

Looney, J.E., C. Ma, T.-H. Leu, W.F. Flintoff, W.B. Troutman, and J.L. Hamlin. 1988. The DHFR amplicons in different Mtx-resistant Chinese hamster cell lines share at least a 273kilobase core sequence, but the amplicons in some cell lines are much larger and are remarkably uniform in structure. Mol. Cell. Biol. 8: 5268-5279.

Mariani, B.D. and R.T. Schimke. 1984. Gene amplification in a single cell cycle in Chinese hamster ovary cells. J. Biol. Chem. 259: 1901-1910. 
McClintock, B. 1984. The significance of responses of the genome to challenge. Science 226: 792-801.

Meinkoth, J. and G.M. Wahl. 1984. Hybridization of nucleic acids immobilized on solid supports. Anal. Biochem. 138: $267-284$.

Milbrandt, J.D., N.H. Heintz, W.C. White, S.M. Rothman, and J.L. Hamlin. 1981. Methotrexate-resistant $\mathrm{CHO}$ cells have amplified a 135 kilobase region that includes the dihydrofolate reductase gene. Proc. Natl. Acad. Sci. 78: 6043-6047.

Nunberg, J.H., R.J. Kaufman, R.T. Schimke, G. Urlaub, and L.A. Chasin. 1978. Amplified dihydrofolate reductase genes are localized to a homogeneously staining region of a single chromosome in a methotrexate-resistant Chinese hamster ovary cell line. Proc. Natl. Acad Sci. 75: 5553-5556.

Passananti, C., B. Davies, M. Ford, and M. Fried. 1987. Structure of an inverted duplication formed as a first step in a gene amplification event: Implications for a model of gene amplification. $E M B O$ I. 6: 1697-1703.

Pinkel, D., T. Straume, and J.W. Gray. 1986. Cytogenetic analysis using quantitative, high sensitivity, fluoresence hybridization. Proc. Natl. Acad. Sci. 83: 2934-2938.

Rice, G.C., V. Ling, and R.T. Schimke. 1987. Frequencies of independent and simultaneous selection of Chinese hamster cells for methotrexate and dioxorubicin (adriamycin) resistance. Proc. Natl. Acad. Sci. 84: 9261-9264

Riva, P., C.D.G. Morghen, and L. Larizza. 1989. Involvement of unstable chromosomal regions containing $\mathrm{C}$-heterochromatin and fragile sites in the integration of amplified DHFR domains. Somatic Cell Mol. Genet. 5: 377-385.

Ruiz, J.C. and G.M. Wahl. 1988. Formation of an inverted duplication can be an initial step in gene amplification. Mol. Cell. Biol. 8: 4302-4313.

1990. Chromsomal destabilization during gene amplification. Mol. Cell. Biol. 10: 3056-3066.

Saito, I. and G.R. Stark 1986. Charomids: Cosmid vectors for efficient cloning and mapping of large or small restriction fragments. Proc. Natl. Acad. Sci. 83: 8664-8668.

Saito, I., R. Groves, E. Giulotto, M. Rolfe, and G.R. Stark. 1989. Evolution and stability of chromosomal DNA coamplified with the CAD gene. Mol. Cell. Biol. 9: 2445-2452.

Schlmke, R.T., S.W. Sherwood, A.B. Hill, and R.N. Johnston. 1986. Over-replication and recombination of DNA in higher eukaryotes: Potential consequences and biological implications. Proc. Natl. Acad. Sci. 83: 2157-2161.

Stark, G.R. and G.M. Wahl. 1984. Gene amplification. Annu. Rev. Biochem. 53: 447-491.

Stark, G.R., M. Debatisse, E. Giulotto, and G.M. Wahl. 1989. Recent progress in understanding mechanisms of mammalian DNA amplification. Cell 57: 901-908.

Szostak, J.W., T.L. Orr-Weaver, R.J. Rothstein, and F.W. Stahl. 1983. The double-strand break region repair model for recombination. Cell 33: 25-35.

Thomas, K. and M.R. Capecchi. 1987. Site-directed mutagenesis by gene targeting in mouse embryo-derived stem cells. Cell 52: 503-512.

Tlsty, T.D. 1990. Normal diploid human and rodent cells lack a detectable frequency of gene amplification. Proc. Natl. Acad. Sci. 87: 3123-3136.

Tlsty, T.D., P.C. Brown, R. Johnston, and R.T. Schimke. 1982. Enhanced frequency of generation of methotrexate resistance and gene amplification in cultured mouse and hamster cell lines. In Gene amplification (ed. R.T. Schimke), pp. 231238. Cold Spring Harbor Laboratory, Cold Spring Harbor, New York.

Tlsty T.D., B.J. Margolin, and K. Lum. 1989. Differences in the rates of gene amplification in nontumorigenic and tumori- genic cell lines as measured by Luria-Delbruck fluctuation analysis. Proc. Natl. Acad. Sci. 86: $9441-9445$.

Trask B.J. and J.L. Hamlin. 1989. Early dihydrofolate reductase gene amplification events in $\mathrm{CHO}$ cells usually occur on the same chromosome arm as the original locus. Genes \& Dev. 3: 1913-1925.

Urlaub, G. and L.A. Chasin. 1980. Isolation of Chinese hamster cell mutants deficient in dihydrofolate reductase activity. Proc. Natl. Acad. Sci. 77: 4216-4220.

Urlaub, G., P.J. Mitchell, E. Kas, L.A. Chasin, V.L. Funanage, T.T. Myoda, and J. Hamlin. 1986. Effects of gamma rays at the dihydrofolate reductase locus: Deletions and inversions. Somatic Cell Mol. Genet. 12: 555-566.

Vogelstein, B., E.R Fearon, S.E. Kern, S.R. Hamilton, A.C. Preisinger, Y. Nakamura, and R. White. 1989. Allelotype of colorectal carcinomas. Science 244: 207-211.

Von Hoff, D.D., B. Forseth, C.N. Clare, K.L. Hansen, and D. VanDevanter. 1990. Double minutes arise from circular extrachromosomal DNA intermediates which integrate into chromosomal sites in human HV60 leukemia cells. I. Clin. Invest. 85: 1887-1895.

Wahl, G.M. 1989. The importance of circular DNA in mammalian gene amplification. Cancer Res. 49: 1333-1340.

Wahl, G.M., L. Vitto, and J. Rubnitz. 1983. Co-amplification of rDNA genes with CAD genes in $\mathrm{N}$-(phosphonacetyl)-L-aspartate-resistant Syrian hamster cells. Mol. Cell. Biol. 3: 2066-2075.

Wright, J.A., H.S. Smith, F.M. Watt, C. Hancock, D.L. Hudson, and G.R. Stark. 1990. DNA amplification is rare in normal human cells. Proc. Natl. Acad. Sci. 87: 1791-1795.

Zakian, V.A. 1989. Structure and function of telomeres. Annu. Rev. Genet. 23: 579-604. 


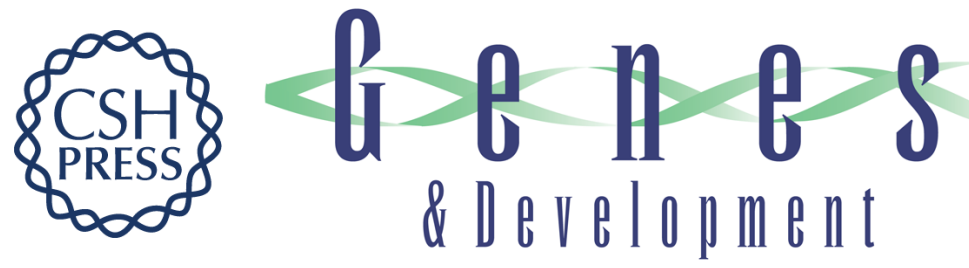

\section{A central role for chromosome breakage in gene amplification, deletion formation, and amplicon integration.}

B Windle, B W Draper, Y X Yin, et al.

Genes Dev. 1991, 5:

Access the most recent version at doi:10.1101/gad.5.2.160

References This article cites 61 articles, 33 of which can be accessed free at:

http://genesdev.cshlp.org/content/5/2/160.full.html\#ref-list-1

License

Email Alerting

Service

Receive free email alerts when new articles cite this article - sign up in the box at the top right corner of the article or click here.

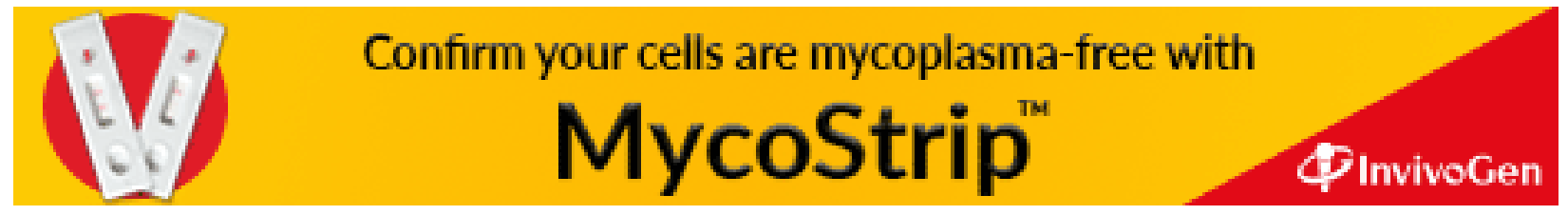

